\title{
Prospective comparison of two methods of screening for diabetic retinopathy by nonmydriatic fundus camera
}

This article was published in the following Dove Press journal:

Clinical Ophthalmology

7 December 2010

Number of times this article has been viewed

\author{
Pedro Romero-Aroca' \\ Ramon Sagarra-Alamo² \\ Josep Basora-Gallisa ${ }^{2}$ \\ Teresa Basora-Gallisa ${ }^{2}$ \\ Marc Baget-Bernaldiz ${ }^{2}$ \\ Angel Bautista-Perez' \\ 'Ophthalmology Service, Hospital \\ Universitario Sant Joan, IISPV, \\ Universidad Rovira I Virgili, \\ ${ }^{2}$ Health Primary Care Region \\ Reus-Priorat, Universidad Rovira I \\ Virgili, Reus, Spain
}

Purpose: To compare the results obtained by two screening techniques for diabetic retinopathy.

Methods: Patients were assessed in two groups, according to whether the retinal images were analyzed by the general practitioner (Group 1) or by the ophthalmologist (Group 2) in a two-year prospective study using telemedicine.

Results: The number of patients referred to the nonmydriatic fundus camera unit was higher in Group 1 than in Group 2 (63.80\% versus 17.63\%). Greater patient adherence was observed in Group 1 than in Group 2 when patients came to retinography (98.25\% versus $87.52 \%$ ). There were no significant differences in other technique variables. The prevalence of diabetic retinopathy was similar in both groups (8.98\% in Group 1 and $9.16 \%$ in Group 2), but the prevalence of severe proliferative diabetic retinopathy was higher in Group 2 (1.69\% [severe] and $0.45 \%$ [proliferative]) than in Group 1 (1.01\% and $0.11 \%$, respectively). Diabetic macular edema was more prevalent in Group 2 (2.03\%).

Conclusions: The inclusion of general practitioners in the screening method seems to be important. A great number of patients with diabetes mellitus were screened, and a higher percentage of patients with diabetic retinopathy or macular edema were detected.

Keywords: nonmydriatic fundus camera, diabetic retinopathy, diabetes mellitus, diabetic macular edema, diabetic retinopathy, epidemiology

\section{Introduction}

Diabetes mellitus is a chronic disease that affects approximately 180 million people around the world. ${ }^{1}$ In 1997, the diagnostic criteria were revised by the World Health Organization, which recognized the two-hour glucose level as a good standard for diagnosis of diabetes, but indicated that a fasting plasma glucose $>7.0 \mathrm{mmol} / \mathrm{L}$ $(126 \mathrm{mg} / \mathrm{dL})$ can be accepted as a satisfactory alternative in epidemiologic studies., ${ }^{2,3}$ These new diagnostic criteria changed the number of patients included as having Type 2 diabetes mellitus and prompted an expected rise estimated at 300 million cases by the year 2025 .

In the Spanish population, the prevalence of diabetes has risen from $6 \%$ in the 1990 s to higher than $12 \%$ in the most recent studies, meaning that there are currently about 4.3 million people with diabetes in Spain. These patients are controlled by family physicians or general practitioners, at primary health care centers, each of which has a dependent population of about 25,000 . The general practitioners refer patients to an ophthalmologist for ocular fundus control and for diabetic retinopathy screening.
Correspondence: Pedro Romero-Aroca C/Ample $55,1^{\circ}$ Health Primary Care Area 43202 Reus (Barcelona), Spain Tel +349773 I 0300 ext 5308

Fax +3 4977323754

Email promero@grupsagessa.com submit your manuscript $\mid$ www.dovepress.com

Dovepress

DOI: $10.2147 /$ OPTH.SI 452 | 
Several different screening methods have been tested, but the most accepted method for community-based screening is retinal photography by nonmydriatic fundus camera. The advantages of this method are becoming increasingly clear, and include low-cost screening, the possibility of extending the screening program to a lot of people with diabetes relatively quickly, taking away the subjectivity in the diagnosis, and being able to maintain accurate records of previous retinal appearances. ${ }^{4,5}$

Since 2005, screening has been done by nonmydriatic fundus camera in our area. Initially, an ophthalmologist evaluated all retinographies, but in January 2007 we introduced evaluation by general practitioners, as the primary diagnostic professionals, although in only half of the primary health care centers. This new method seems to be efficient, as we have reported previously. ${ }^{6}$

The aim of the present study was to compare the results from a two-year prospective study (2008-2009), using two different techniques of diabetic retinopathy screening. The first includes diagnosis by the general practitioners using telemedicine, assisted by an ophthalmologist in the event of a doubtful retinography, and the second including the reading of all retinographies by an ophthalmologist.

\section{Methods}

\section{Study setting}

Hospital Universitari de Sant Joan is the only surgical ophthalmology center in Reus, Spain, with 218,740 inhabitants, and all diabetes patients referred by general practitioners to the hospital are examined once a year by the ophthalmology service. The prevalence of diabetes mellitus in the population over 14 years of age is estimated at $8 \%$; a total of 12,146 patients are considered to have the disease. This study is based on Type 2 diabetes mellitus only; patients with Type 1 were excluded because since 1991 all Type 1 diabetes patients have been screened annually at the hospital by endocrinologists and ophthalmologists.

\section{Design}

Patients were classified in two groups. In Group 1, screening for diabetic retinopathy was done by 73 general practitioners in seven of the 12 primary health care centers in our area (R-I, R-II, R-III, R-IV, PR-I, PR-II, PR-III). These areas represent a total of 113,396 inhabitants including 7133 registered diabetics. A description of this population has been published previously. ${ }^{6}$ In Group 2, screening for diabetic retinopathy was done by an ophthalmologist, and the results were sent on to the general practitioners. This group included
62 general practitioners in five of the 12 primary health care centers in our area (R-V, PR-IV, PR-V, PR-VI, PR-VII). These areas represent a total of 105,344 inhabitants including 5013 registered diabetics.

There were no demographic, social, or economic differences between the two populations, and urban and rural areas were distributed evenly across both groups.

In 2006, prior to the program, the general practitioners in Group 1 were given a short course in the theory and practice of fundus eye exploration and diagnosis that is normally carried out by a retina specialist at the ophthalmology service. In the two groups, the same financial incentives were offered to the general practitioners to refer patients for diabetic retinopathy screening. A total of 4551 patients in Group 1 and 884 in Group 2 were examined by nonmydriatic fundus camera between 01 January 2008 and 31 December 2009.

\section{Screening techniques}

Group 1 patients were referred by their general practitioners to the retina fundus camera unit located at one health care center (R-I). A technician was specifically trained to take photographs without pupil dilatation (except in cases where this was not possible, when a drop of tropicamide $0.5 \%$ was given). The retinographies were sent to the general practitioners for diagnosis. If the images were pathologic (in his or her opinion) the general practitioner sent the images on to the referring ophthalmologist, who evaluated them and reported back to the general practitioner, having decided if the patient needed a secondary study or treatment at the ophthalmology retina unit at the hospital.

Group 2 patients were referred by their general practitioners to the retina fundus camera unit located at one health care center (R-V) as for Group 1. A technician was specifically trained to take photographs without pupil dilatation (except in cases where this was not possible, when a drop of tropicamide $0.5 \%$ was given). However, diagnosis was then made by the ophthalmologist, who sent a report of the status of the fundus to the general practitioner, recommending or not a secondary study or treatment in the ophthalmology retina unit at the hospital.

Both groups referred to the same ophthalmologist. He read the doubtful retinographies in Group 1 and all retinographies in Group 2. The retina was photographed using a unit equipped with a TOPCON TRC-NW6S fundus camera. Two nonstereoscopic $45^{\circ}$ photographs were taken of each eye, according to the EURODIAB recommended protocol; two photographs in two fields were taken, the first centered on the temporal to the macula and the second on 
the nasal to the papilla. $^{7}$ Age, type, duration, and treatment of diabetes, and any history of arterial hypertension, as well as $\mathrm{HbA}_{1 \mathrm{c}}$ and lipid levels, were recorded.

\section{Diagnosis and classification of diabetic retinopathy}

Diabetic retinopathy is diagnosed when at least four or more microaneurysms are present in the fundus photograph, with or without hard or soft exudates, in the absence of other known causes of the changes (eg, branch retinal vein occlusion).

According to a modified version of the American Academy of Ophthalmology classification, ${ }^{8,9}$ seven grades of severity were established, ie, nondiabetic retinopathy, mild nonproliferative diabetic retinopathy, moderate nonproliferative diabetic retinopathy, severe nonproliferative diabetic retinopathy, proliferative diabetic retinopathy without high-risk characteristics, proliferative diabetic retinopathy with high-risk characteristics, and patients treated previously with laser. Because the presence of retinal thickening with no hard exudates is difficult to detect from our nonstereoscopic digital images, grading of maculopathy was based on the presence of exudates in the macular region. The existence of hard exudates at 500 microns from the fovea was considered to be diagnostic of macular edema in the present study.

\section{Statistical methods}

All statistical analyses were carried out using the SPSS software package version 15.0. Results were expressed as mean \pm standard error, and a $P$ value $<0.05$ was considered to indicate statistical significance. Differences between those included in the analysis were examined using two sample Student $t$-tests or Kruskal-Wallis for continuous or quantitative variables, such as visual acuity or current age. For the qualitative or categorical variables, we used the Chi-square test in the univariate phase of the study, with determination of the odds ratio for each variable.

Variables included in the study were presence of diabetic retinopathy, presence of diabetic macular edema, and presence of any lesion in the macular area (eg, age-related maculopathy, macular degeneration, myopia, epiretinal membranes).

\section{Results}

In Group 1, 4551 patients were screened. The mean age was $64.52 \pm 12.46$ years (40-91 years), with 2093 men (45.98\%) and 2458 women (54.08\%, Table 1$)$. The mean duration of diabetes mellitus was $7.56 \pm 4.09$ (1-30) years. Arterial hypertension was present in 2585 patients $(56.80 \%)$. Diabetes was treated with insulin in 1282 patients $(28.17 \%)$. In Group 2, 884 patients were screened. Mean age was $64.47 \pm 12.13$ years (38-90 years), with 403 men $(45.51 \%)$ and 481 women $(54.42 \%)$. Mean duration of diabetes mellitus was $7.54 \pm 4.12(1-25)$ years. Arterial hypertension was present in 499 patients $(56.45 \%)$. Diabetes was treated with insulin in 229 patients $(25.90 \%)$

In Group 1, general practitioners referred 4632 patients $(64.93 \%)$ to the fundus camera unit, of whom 4551 attended the visit $(98.25 \%)$, representing $63.80 \%$ of all patients registered as diabetic (Tables 2 and 3). Pupil dilatation was necessary in 1229 cases $(27.00 \%)$. For 97 patients $(2.13 \%)$, it was not possible to interpret the fundus image, so the image was referred to an ophthalmologist for further examination under slit-lamp biomicroscopy. There were $2.92 \pm 0.67$ photographs taken of each patient to obtain the best quality retinography. General practitioners

Table I Demographic and metabolic data for the patients at the end of two years

\begin{tabular}{|c|c|c|c|}
\hline & Group I & Group 2 & Significance $(P)$ \\
\hline Total patients screened & 4551 & 884 & \\
\hline Male/female & $\begin{array}{l}2093 / 2458 \\
(45.99 \% / 54.01 \%)\end{array}$ & $\begin{array}{l}406 / 478 \\
(45.93 \% / 54.07 \%)\end{array}$ & 0.127 \\
\hline Age $($ mean $\pm S D)$ & $\begin{array}{l}64.52 \pm 12.46 \\
(40-91 \text { years })\end{array}$ & $\begin{array}{l}64.47 \pm 12.13 \\
(38-90 \text { years })\end{array}$ & 0.157 \\
\hline Diabetes duration (mean $\pm \mathrm{SD}$ ) & $\begin{array}{l}7.56 \pm 4.09 \\
(1-30 \text { years })\end{array}$ & $\begin{array}{l}7.54 \pm 4.12 \\
(1-25 \text { years })\end{array}$ & 0.213 \\
\hline Arterial hypertension & 2594 (56.99\%) & 495 (55.99\%) & 0.112 \\
\hline \multicolumn{4}{|l|}{ Diabetes treatment } \\
\hline Diet & $473(16.99 \%)$ & I 44 ( $16.28 \%)$ & 0.113 \\
\hline Oral & $2594(56.99 \%)$ & $495(55.99 \%)$ & 0.332 \\
\hline Insulin & I I 84 (26.02\%) & 245 (27.7I\%) & 0.241 \\
\hline $\mathrm{HbA}_{\mathrm{Ic}}$ & $7.64 \pm 1.34$ & $7.54 \pm 1.08$ & 0.316 \\
\hline
\end{tabular}

Abbreviations: SD, standard deviation; $\mathrm{Hba}_{\mathrm{Ic}}$, glycosylated hemoglobin. 
Table 2 Different results between screening methods, data after two years (0I January 2008 to 3I December 2009)

\begin{tabular}{|c|c|c|c|}
\hline & Group I $(n=455 I)$ & Group $2(n=884)$ & Significance $(P)$ \\
\hline $\begin{array}{l}\text { Number of patients referred to the screening/number } \\
\text { of patients registered as diabetic }\end{array}$ & $4632 / 133(64.93 \%)$ & $1010 / 5013(20.14 \%)$ & $<0.001$ \\
\hline $\begin{array}{l}\text { Number of patients screened/number } \\
\text { of patients registered as diabetic }\end{array}$ & $455 \mathrm{I} / 7 \mathrm{I} 33$ (63.80\%) & $884 / 5013(17.63 \%)$ & $<0.001$ \\
\hline $\begin{array}{l}\text { Number of patients screened/number } \\
\text { of patients referred }\end{array}$ & $455 \mathrm{I} / 4632$ (98.25\%) & $884 / 1010$ (87.52\%) & $<0.001$ \\
\hline $\begin{array}{l}\text { Number of patients who did not } \\
\text { attend the retinography }\end{array}$ & $81 / 4632(1.75 \%)$ & $126 / 1010(12.47 \%)$ & $<0.001$ \\
\hline No visualization of retinography & 60/455I (2.15\%) & I8/884 (2.04\%) & 0.228 \\
\hline Pupil dilatation needed & $|229 / 455|(27.00 \%)$ & $238 / 884(26.92 \%)$ & 0.113 \\
\hline Number of retinographies per eye & $2.92 \pm 0.67$ & $2.87 \pm 0.65$ & 0.103 \\
\hline $\begin{array}{l}\text { Number of patients referred to the ophthalmology } \\
\text { service after screening }\end{array}$ & $387 / 455$ I (8.50\%) & $77 / 884(8.71 \%)$ & 0.073 \\
\hline Retinography waiting list & $15.23 \pm 3.12$ days & $14.12 \pm 2.98$ days & 0.127 \\
\hline
\end{tabular}

referred the retinographies of 956 patients $(21.01 \%)$ to the consultant ophthalmologist. Of those, the ophthalmologist sent on 409 patients $(8.98 \%)$ to the retina section of the ophthalmology service for the correct diagnostic procedure and treatment. In Group 2, general practitioners referred 1010 patients $(20.14 \%)$ to the fundus camera unit, of whom 884 attended the visit $(87.52 \%)$, representing $17.63 \%$ of all patients registered as diabetic. Pupil dilation was necessary in 238 patients $(26.92 \%)$. For 19 patients $(2.14 \%)$, it was not possible to interpret the fundus image, and these patients needed referral to the ophthalmologist for further examination under slit-lamp biomicroscopy. There were $2.87 \pm 0.65$ photographs taken of each patient to obtain the best quality retinography. Of those, general practitioners referred 79 patients $(8.93 \%)$ to the ophthalmology service for the correct diagnostic procedure and treatment.

In Group 1, diabetic retinopathy was diagnosed in 409 patients $(8.98 \%)$ and diabetic macular edema in 60 patients $(1.32 \%)$. Diabetic retinopathy was classified as mild in 227 patients (4.98\%), 88 patients (1.93\%) presented with moderate diabetic retinopathy, 46 patients $(1.01 \%)$ had severe diabetic retinopathy, and only five patients $(0.11 \%)$ had a proliferative form of the disease (Table 4$)$. There were $43(0.94 \%)$ patients previously treated by laser. In Group 2 , diabetic retinopathy was diagnosed in 81 patients $(9.16 \%)$ and diabetic macular edema in 18 patients (2.03\%). Diabetic retinopathy was classified as mild in 43 patients $(4.86 \%)$, moderate in $17(1.92 \%)$, severe in $13(1.47 \%)$, and four

Table 3 Index of referred patients to the nonmydriatic fundus camera during the two-year study, and subclassified into two groups according to primary health care center

\begin{tabular}{|c|c|c|c|c|c|c|c|c|}
\hline & $\begin{array}{l}\text { R-I } \\
\text { Urban }\end{array}$ & $\begin{array}{l}\text { R-II } \\
\text { Urban }\end{array}$ & $\begin{array}{l}\text { R-III } \\
\text { Urban }\end{array}$ & $\begin{array}{l}\text { R-IV } \\
\text { Urban }\end{array}$ & $\begin{array}{l}\text { PR-I } \\
\text { Rural }\end{array}$ & $\begin{array}{l}\text { PR-II } \\
\text { Rural }\end{array}$ & $\begin{array}{l}\text { PR-III } \\
\text { Rural }\end{array}$ & Total \\
\hline \multicolumn{9}{|l|}{ Group I } \\
\hline $\begin{array}{l}\text { Registered } \\
\text { diabetic patients }\end{array}$ & 1064 & 1916 & 1492 & 1382 & 170 & 416 & 693 & 7133 \\
\hline 2008 & $272(25.56 \%)$ & 556 (29.0।\%) & $310(20.77 \%)$ & 544 (39.36\%) & $31(18.23 \%)$ & 94 (22.60\%) & 209 (30.15\%) & $2016(28.26 \%)$ \\
\hline 2009 & 400 (37.59\%) & 667 (34.8I\%) & 466 (3I.23\%) & 639 (46.23\%) & 35 (20.58\%) & IOI (24.27\%) & 227 (32.75\%) & 2535 (35.54\%) \\
\hline $\begin{array}{l}\text { Total (two-year } \\
\text { summary) }\end{array}$ & $672(63.16 \%)$ & I 223 (63.83\%) & 776 (52\%) & I I 83 (85.60\%) & 66 (38.82\%) & I 95 (46.87\%) & 436 (62.9l\%) & $455 \mathrm{I}(63.80 \%)$ \\
\hline Group 2 & $\begin{array}{l}\text { R-V } \\
\text { Urban }\end{array}$ & $\begin{array}{l}\text { PR-IV } \\
\text { Rural }\end{array}$ & $\begin{array}{l}\text { PR-V } \\
\text { Urban }\end{array}$ & $\begin{array}{l}\text { PR-VI } \\
\text { Urban }\end{array}$ & $\begin{array}{l}\text { PR-VII } \\
\text { Rural }\end{array}$ & Total & & \\
\hline $\begin{array}{l}\text { Registered } \\
\text { diabetic patients }\end{array}$ & 1735 & 401 & 1792 & 730 & 355 & 5013 & & \\
\hline 2008 & $13 \mid(9.10 \%)$ & III (34.16\%) & I57 (I0.26\%) & $56(8.70 \%)$ & $13(3.30 \%)$ & 468 (9.33\%) & & \\
\hline 2009 & 130 (10.23\%) & 72 (22.08\%) & 206 (13.76\%) & 7 (1.01\%) & I (0.34\%) & 416 (8.29\%) & & \\
\hline $\begin{array}{l}\text { Total (two-year } \\
\text { summary) }\end{array}$ & 261 (19.33\%) & I83 (56.24\%) & $363(24.02 \%)$ & $63(9.71 \%)$ & 14 (3.64\%) & 884 (17.63\%) & & \\
\hline
\end{tabular}


Table 4 Classification of patients with diabetic retinopathy and diabetic macular edema

\begin{tabular}{llll}
\hline Type of DR & $\begin{array}{l}\text { Group I } \\
(\mathbf{n}=\mathbf{4 5 5} \mathbf{I})\end{array}$ & $\begin{array}{l}\text { Group 2 } \\
(\mathbf{n}=\mathbf{8 8 4}) \\
\mathbf{n}(\%) \text { of patients }\end{array}$ & $\begin{array}{l}\text { Significance }(\boldsymbol{P}) \text { between } \\
\text { groups I and 2 }\end{array}$ \\
\hline Mild & $227(4.98 \%)$ & $41(4.63 \%)$ & 0.062 \\
Moderate & $88(1.93 \%)$ & $17(1.92 \%)$ & 0.175 \\
Severe & $46(1.01 \%)$ & $15(1.69 \%)$ & $<0.001$ \\
Proliferative & $5(0.11 \%)$ & $4(0.45 \%)$ & $<0.001$ \\
LTP & $43(0.94 \%)$ & $4(0.45 \%)$ & 0.02 \\
Total with DR & $409(8.98 \%)$ & $81(9.16 \%)$ & $0.08 \mathrm{I}$ \\
DME* & $60(1.32 \%)$ & $18(2.03 \%)$ & $<0.001$ \\
\hline
\end{tabular}

Note: *DME: patients' included as DME were included in the total DR data, and distributed according to its severity.

Abbreviations: DME, diabetic macular edema; DR, diabetic retinopathy; LTP, treatment with laser.

patients $(0.45 \%)$ had a proliferative form of the disease. There were four $(0.45 \%)$ patients previously treated by laser.

In 470 patients (10.32\%) in Group 1 we observed retinal pathologies different from diabetic retinopathy (Table 5). The most frequent were lesions compatible with age-related macular degeneration in 82 patients $(1.80 \%)$, drusen in the macular area in 109 patients $(2.39 \%)$, hypopigmented and hyperpigmented lesions in the macular area in 49 patients (1.07\%), and lesions in the macular area in $290(6.37 \%)$ patients (including diabetic macular edema, age-related macular degeneration, age-related maculopathy, drusen, myopia, and epiretinal membranes). The group of patients with pupillary dilatation showed no differences in the diagnoses observed. In Group 2, we observed retinal pathologies different from diabetic retinopathy in 96 patients $(10.86 \%)$. The most frequent were lesions compatible with age-related macular degeneration in 16 patients $(1.81 \%)$, drusen in the macular area in 21 patients (2.37\%), hypopigmented and hyperpigmented lesions in the macular area in 11 patients $(1.24 \%)$, and lesions in the macular area in $58(6.56 \%)$ patients (including diabetic macular edema, age-related macular degeneration, age-related maculopathy, drusen, myopia, epiretinal membranes). The group of patients with pupillary dilatation showed no differences in the diagnoses observed.

Each of the tables shows statistically significant differences between the two groups. There were no differences according to age and gender or in arterial hypertension or treatment of diabetes. There were differences between the groups with respect to adherence to the scheduled visit to the nonmydriatic fundus camera unit (Tables 2 and 3). A greater number of patients registered as diabetics were screened in Group 1, and more of those patients attended the visits.

Table 4 shows that the prevalence of diabetic retinopathy was similar in both groups, with no significant differences $(P=0.081)$. However, statistical analysis revealed some differences between the groups. In Group 2, the worst forms of diabetic retinopathy (severe diabetic retinopathy and proliferative diabetic retinopathy) were more prevalent. There were also differences in the number of patients undergoing laser treatment, which was higher in Group 1. There were no significant differences between the groups with regard to other pathologies.

\section{Discussion}

Systematic screening for diabetic retinopathy has been identified as a cost-effective use of health service resources,

Table 5 Other types of retinal lesions observed in the study, showing statistical differences between groups

\begin{tabular}{|c|c|c|c|}
\hline \multirow[t]{2}{*}{ Pathology } & \multirow{2}{*}{$\begin{array}{l}\text { Group I } \\
(n=455 I) \\
n(\%) \text { of patients }\end{array}$} & \multirow{2}{*}{$\begin{array}{l}\text { Group } 2 \\
(n=884) \\
n(\%) \text { of patients }\end{array}$} & \multirow[t]{2}{*}{$\begin{array}{l}\text { Significance }(P) \text { between } \\
\text { groups } I \text { and } 2\end{array}$} \\
\hline & & & \\
\hline $\begin{array}{l}\text { Age-related macular } \\
\text { degeneration }\end{array}$ & $82(1.80 \%)$ & $16(1.81 \%)$ & 0.113 \\
\hline Macular drusen & 109 (2.39\%) & 21 (2.37\%) & 0.201 \\
\hline Periphery drusen & $56(1.23 \%)$ & $10(1.13 \%)$ & 0.112 \\
\hline $\begin{array}{l}\text { Hypo-/hyperpigmented } \\
\text { lesions }\end{array}$ & 49 (1.07\%) & II (I.24\%) & 0.060 \\
\hline Myopia in macular area & $50(1.09 \%)$ & $10(1.13 \%)$ & 0.097 \\
\hline Other diagnoses & $127(2.79 \%)$ & $28(3.16 \%)$ & 0.250 \\
\hline Total & 470 (10.32\%) & 96 (10.86\%) & 0.140 \\
\hline
\end{tabular}


with national screening programs based on digital photography being implemented across Europe. ${ }^{10-12,16}$ The previous system included the referral of all diabetes patients to the hospital, retinography by a technician, and the study of all images and subsequent reporting by an ophthalmologist. ${ }^{13-15}$ The inclusion of general practitioners in the screening program might help us to avoid excessive referrals of patients to hospital. In a previous study, we demonstrated that, after correct training and direct support by an ophthalmologist in close collaboration with the general practitioner, the screening of diabetic retinopathy could be undertaken by primary health care centers. ${ }^{6}$ This study describes a system that has given general practitioners the responsibility for referring any pathologic retinal images to a retina specialist via the virtual private network common to any primary care unit and hospital ophthalmology service. This new development may help us to approach diabetes control by fundus camera through primary care health professionals and may involve general practitioners.

In this study, we have used the EURODIAB protocol which recommends two photographs in two $45^{\circ}$ fields, the first centered on the temporal to the macula and the second on the nasal to the papilla, which has proven effective in diabetic retinopathy screening in other studies., ${ }^{7,16,17}$ The demographic characteristics of the two groups were similar, and are consistent with the literature on diabetes mellitus. ${ }^{18}$ This similarity has allowed us to compare the groups and study them statistically.

We can see in Table 3 that 4551 patients $(63.80 \%$ of all registered diabetics) in Group 1 were screened versus just $884(17.63 \%)$ in Group 2. This is surprising, if we consider that the financial incentives and the waiting list for screening are similar in both groups. We do not believe that the urban or rural origin of the patients influenced the results, because both groups had a similar demographic distribution. We can suppose that the greater involvement of general practitioners in the Group 1 cohort has made an observable difference.

Table 2 also presents data that is similar for both groups, but with differences in the number of patients requiring pupil dilatation, number of retinographies per eye, and number of patients referred to the ophthalmology service. However, these differences are not statistically significant.

The prevalence of diabetic retinopathy is similar in both groups and not statistically significant. Taking into account the percentage of patients with diabetic retinopathy, we observed that the prevalence was $8.37 \%$ in Group 1 and $9.16 \%$ in Group 2. These levels are inferior to those in other published cross-sectional studies, ${ }^{18,19}$ but we should point out that the screening was carried out in diabetic patients who had not been diagnosed previously, because the latter were being monitored by the ophthalmology department. Furthermore, in studies with similar methods, such as that published by Soulié-Strougar in France, ${ }^{20}$ the prevalence of diabetic retinopathy was found to be $8.57 \%$.

In the present study, there were some differences in the severity of diabetic retinopathy between the groups. Group 1 had fewer patients with severe and proliferative diabetic retinopathy, which was significant in statistical analysis $(P=0.04$ for severe diabetic retinopathy and $P<0.001$ for proliferative diabetic retinopathy). There was also a significant difference $(P=0.04)$ in the number of patients who had laser treatment $(0.94 \%$ in Group 1 versus $0.79 \%$ in Group 2). Finally, diabetic macular edema was more prevalent in Group $2(2.03 \%$ versus $1.32 \%$ in Group 1), and the differences are also significant in statistical analysis. Although we could detect the influence of general practitioners in Group 1, due to the small number of patients screened in Group 2 (17.63\%), we cannot rule out that any change in a single patient to a more severe form of diabetic retinopathy may have altered the outcome.

It is important that severe and proliferative forms of diabetic retinopathy are correctly diagnosed by general practitioners and that the patients with these deleterious forms of the disease, which may cause marked deterioration in visual acuity, are treated promptly in an ophthalmology department. Important in this study was the diagnosis of supposed diabetic macular edema. It is noteworthy that, of all cases detected with the nonmydriatic fundus camera, the diagnosis of clinically significant macular edema was confirmed by biomicroscopy, and that focal laser photocoagulation was carried out in those patients. The diagnosis of diabetic macular edema is important because it is the leading cause of blindness in patients with Type 2 diabetes mellitus. Despite some studies describing the spontaneous disappearance of diabetic macular edema in up to $30 \%$ of cases, ${ }^{21,22}$ we think it is important to detect and treat these types of diabetic macular lesions. Furthermore, it is important that patients with severe macular lesions, such as age-related macular degeneration, macular drusen, and myopia in the macular area, are correctly diagnosed by general practitioners.

Finally, we should bear in mind that if we extrapolate the results and consider that $63.80 \%$ of patients with diabetes mellitus were screened in Group 1, we may surmise 
that in Group 2 as many as 203 patients with diabetic retinopathy were not detected (78 of them with severe or proliferative diabetic retinopathy), and 42 patients with diabetic edema macular went undetected, which may have caused the loss of visual acuity in about 120 patients in Group 2.

In diseases for which diagnosis is based mainly on imaging, as in diabetic retinopathy, the contribution of new imaging technology is essential. The possibility of using nonmydriatic cameras allows interaction between the different health care professionals who examine patients with diabetes. The differences between the two methods of screening do seem to be important, and the inclusion of general practitioners in the diagnosis of diabetic retinopathy appears to be advantageous. It is important to note that, in the present study, the 73 participating general practitioners from 135 in our area were chosen at random and were not selected according to any specific criteria, although they were given special training in order to be able to evaluate the images. The results are more significant in view of the fact that the general practitioners included in Group 1 showed a varying degree of interest in taking part in the program. Some showed a lot of interest from the start and others not so much, but, despite that, there was a good response from all of them a few months into the program.

The weakness of this study is the small number of patients in Group 2, which could have influenced the results, considering that the health care centers for Group 2 had a high number of patients with severe diabetic retinopathy, and a low number of patients successfully treated by laser, but this can be due only to the limited number of patients referred to the nonmydriatic fundus camera unit.

\section{Conclusion}

The implementation of a nonmydriatic fundus camera unit in our region may help us to control the diabetes population more strictly. Moreover, the inclusion of the general practitioner in the screening method (Group 1) seems to be important, and a great number of patients with diabetes mellitus were screened, with a higher percentage of patients with diabetic retinopathy or macular edema detected.

\section{Acknowledgments}

The authors thank all the general practitioners who helped to implement the new system of screening by nonmydriatic fundus camera and to our camera technicians for their work and interest in the new method.

\section{Disclosure}

The authors report no conflicts of interest in this work.

\section{References}

1. World Health Organization. Diabetes Mellitus. Report of a WHO Study Group Geneva. World Health Organization. Tech Rep Ser No 727. 1985:1-113. Available at: http://www.google.co.nz/\#hl=en\& source $=\mathrm{hp} \&$ biw $=980 \& \mathrm{bih}=588 \& \mathrm{q}=$ World + Health + Organization.+ Diabetes+Mellitus.+Report+of+a+WHO+Study+Group+Geneva.+ World +Health+Organization. + Tech + Rep + Ser+No+727\&btnG $=$ Google+Search\&rlz=1W1GZEZ_en-GB\&aq=f\&aqi $=\& a q 1=\& o q=$ World + Health+Organization.+Diabetes+Mellitus.+Report+of+a+ $\mathrm{WHO}+$ Study+Group+Geneva.+World+Health+Organization.+ Tech+Rep+Ser+No+727\&gs_rfai $=\& f p=a 779 e 1 d 267003 a 5 e$. Accessed 2010 Nov 4

2. Report of the Expert Committee on the diagnosis and classification of diabetes mellitus. American Diabetes Association. Diabetes Care. 1997;20:1183-1201.

3. Clinical practice recommendations. American Diabetes Association. Diabetes Care. 2002;25 Suppl 1:S1-S147.

4. Orozco-Beltran D, Cos-Claramunt FX. Primary care diabetes in Spain. Prim Care Diabetes. 2008;2:101-103.

5. Castell C, Tresserras R, Lloveras G, Goday A, Serra J, Salleras L. Prevalence of diabetes in Catalonia, an OGTT-based population study. Diab Res Clin Prac. 1999;43:33-40.

6. Romero P, Sagarra R, Ferrer J, Fernandez-Ballart J, Baget M. The incorporation of family physicians in the assessment of diabetic retinopathy by non-mydriatic fundus camera. Diabetes Res Clin Pract. 2010;88:184-188.

7. Aldington SJ, Kohner EM, Meuer S, Klein R, Sjolie AK. Methodology for retinal photography and assessment of diabetic retinopathy. The EURODIAB IDDM complications study. Diabetologia. 1995; $38: 437-444$

8. Grading diabetic retinopathy from stereoscopic color fundus photographs. An extension of the modified Airli House classification. ETDRS report number 10. Early Treatment Diabetic Retinopathy Study Research Group. Ophthalmology. 1991;98 Suppl 5:786-806.

9. Wilkinson CP, Ferris FL, Klein RE, et al. Global Diabetic Retinopathy Project Group. Proposed international clinical diabetic retinopathy and diabetic macular edema disease severity scales. Ophthalmology. 2003; 110:1677-1682.

10. Buxton MJ, Sculpher MJ, Ferguson BA, et al. Screening for treatable diabetic retinopathy: A comparison of different methods. Diabet Med. 1991;8:371-377.

11. Gómez-Ulla F, Fernandez MI, Gonzalez F, et al. Digital retinal images and teleophthalmology for detecting and grading diabetic retinopathy. Diabetes Care. 2002;28:1384-1389.

12. Scanlon PH, Malhotra R, Thomas G, et al. The effectiveness of screening for diabetic retinopathy by digital imaging photography and technician ophthalmoscopy. Diabet Med. 2003;20:467-474.

13. Kraft SK, Marrero DG, Lazaridis EN, Fineberg N, Qiu C, Clark CM Primary care physicians' practice patterns and diabetic retinopathy. Current levels of care. Arch Fam Med. 1997;6:29-37.

14. Awh CC, Javitt JC, Chong LP, Gehrs KM, Gusman GI, Street DA. Ophthalmoscopic diagnosis and referral of diabetic eye disease by primary care physicians. Invest Ophthalmol Vis Sci. 1993; 34:713.

15. Verma L, Prakash G, Tewari HK, Gupta SK, Murthy GV, Sharma N. Screening for diabetic retinopathy by non-ophthalmologists: An effective public health tool. Acta Ophthalmol Scand. 2003;81: 373-377.

16. Hutchinson A, McIntosh A, Peters J, et al. Effectiveness of screening and monitoring tests for diabetic retinopathy a systematic review. Diabet Med. 2000;17:495-506. 
17. Kuo HK, Hsieh HH, Liu RT. Screening for diabetic retinopathy by one-field, non-mydriatic $45^{\circ}$ digital photography is inadequate. Ophthalmologica. 2005;219:292-296.

18. Klein R, Klein BE, Moss SE, et al. The Wisconsin Epidemiologic Study of Diabetic Retinopathy: XVII. The 14-year incidence and progression of diabetic retinopathy and associated risk factors in type 1 diabetes. Ophthalmology. 1998;105:1801-1815.

19. Romero-Aroca P, Fernández-Balart J, Baget-Bernaldiz M, et al. Changes in the diabetic retinopathy epidemiology after 14 years in a population of Type 1 and 2 diabetic patients after the new diabetes mellitus diagnosis criteria and a more strict control of the patients. J Diabetes Complications. 2009;23:229-238.
20. Soulié-Strougar M, Charles A, Métral P, et al. Screening diabetic retinopathy in Burgundy with an itinerant nonmydriatic camera. $J$ Fr Ophtalmol. 2007;30:121-126. French.

21. Early Treatment Diabetic Retinopathy Study Research Group. Early photocoagulation for diabetic macular retinopathy. ETDRS report number 9. Ophthalmology. 1991;98:766-785.

22. Hikichi T, Fujio N, Akiba J, Azuma Y, Takahashi M, Yoshida A. Association between the short-term natural history of diabetic macular oedema and the vitreomacular relationship in type II diabetes mellitus. Ophthalmology. 1997;104:473-478.
Clinical Ophthalmology

\section{Publish your work in this journal}

Clinical Ophthalmology is an international, peer-reviewed journal covering all subspecialties within ophthalmology. Key topics include: Optometry; Visual science; Pharmacology and drug therapy in eye diseases; Basic Sciences; Primary and Secondary eye care; Patient Safety and Quality of Care Improvements. This journal is indexed on

\section{Dovepress}

PubMed Central and CAS, and is the official journal of The Society of Clinical Ophthalmology (SCO). The manuscript management system is completely online and includes a very quick and fair peer-review system, which is all easy to use. Visit http://www.dovepress.com/ testimonials.php to read real quotes from published authors. 